\title{
Do Demographics Matter in Consumer Materialism?
}

\author{
Dalia Antiniene ${ }^{1}$, Beata Seinauskiene ${ }^{2}$, Ausra Rutelione ${ }^{3}$, Shahrokh Nikou ${ }^{4}$, Rosita Lekaviciene ${ }^{5}$
}

${ }^{1}$ Department of Health Psychology, Lithuanian University of Health Sciences

A. Mickeviciaus st. 9, 44307, Kaunas Lithuania

E-mail.dalia.antiniene@lsmuni.lt

${ }^{2,3,5}$ Kaunas University of Technology

K. Donelaicio st. 73, 44029, Kaunas, Lithuania

E-mail. ${ }^{2}$ beata.seinauskiene@ktu.lt; ${ }^{3}$ ausra.rutelione@ktu.lt; ${ }^{5}$ rosita.lekaviciene@ktu.lt

${ }^{4}$ A bo Akademi University

Fanriksgatan 3B, 20500 Turku, Finland

Stockholm University

Nodhuset, Borgarfjordsgatan 12, 16407 Kista, Sweden

E-mail.shahrokh.nikou@abo.fi

cross $^{\text {ref }}$ http://dx.doi.org/10.5755/j01.ee.32.4.28717

This paper aims to investigate the effects of personal characteristics such as gender, income, education and age on consumer materialism. Research hypotheses are based on both existing marketing literature and an additional integration of gender studies literature in order to further the study of materialism. By using random sampling and surveying 1000 respondents living across different regions in Lithuania, the results show significant differences along gender, age, self-perceived relative income and education in terms of consumers' materialistic dispositions. The study confirms that younger consumers are more inclined to materialistic values than older ones. Women differ from men on materialism centrality, as well as happiness and success measures. Regarding consumers' self-perceived relative income, Lithuanians with low income are more prone to aspire to material possessions. Furthermore, research indicates higher rates of consumer materialism to appear among less educated individuals. This is one of the first representative studies in Lithuania revealing what effects different demographic consumer characteristics have on materialistic behaviour. Our findings have some practical implications; for example, they show that vulnerable segments of the population are more susceptible to materialism, necessitating educational policies to reduce such behavior and encourage a more responsible approach. As a result, these educational programs should be tailored to these individuals, with a greater emphasis on the risks associated with overconsumption.

Keywords: Consumer Materialism; Age; Gender; Income; Education.

\section{Introduction}

With consumption culture gaining ground worldwide, researchers continue to be attentive to the causes of materialistic preoccupations, which have been proved to be detrimental to individual and societal well-being (Dittmar et al., 2014; Moldes \& Ku, 2020). Highly materialistic consumers exhibit lower satisfaction with life and demonstrate higher anxiety and depression rates, resulting in poorer mental health overall (Kasser \& Ryan, 1993, 1996; Wang et al., 2017). Studies also point to evidence that materialism is negatively associated with academic performance (King \& Datu, 2017). Likewise, the continuous pursuit of materialistic aims is suggested to be conducive to maladaptive consumption (Harnish et al., 2019), which might gradually turn into behavioural addictions such as compulsive buying (Dittmar, 2005a, 2005b). Compulsive buying rates across different countries are a sign of how deeply materialistic culture is ingrained in the contemporary lifestyle, and their expected rise in the future prompts a concern. For example, a recent meta-analysis by Maraz et al. (2016) revealed that, on average, one in twenty consumers suffer from compulsive buying disorder, with the rates being even higher within samples of younger consumers. Such disagreeable behavioural outcomes of materialism are at odds with pro-environmental and sustainability agendas and call for further research on its antecedents.

Earlier studies across twelve countries suggest that the prevalence of materialism is susceptible neither to the economic wealth, nor to the Westernness of different nations. A study by Ger and Belk (1996) found Romanians to exhibit the highest level of materialism, followed by the United States, New Zealand, and Ukraine. In the same study, samples of Germany, Turkey, Israel, and Thailand exhibited moderate levels, while Sweden scored the lowest. More recent research (Zhang et al., 2020) found greater materialism among Chinese students than their Dutch counterparts, suggesting that economic growth may affect developing and developed countries differently. Consumers from developed countries may be satiated with material wealth, and, therefore, more inclined to turn to postmaterialistic values. Such trends are also reflected in a negative association observed between GDP per capita and materialism across 40 nations (Zhou, 2009).

Thus, different socio-cultural backgrounds and developmental trajectories of countries with transitional 
economies may not necessarily lead to the display of similar profiles of materialistic inclinations and their sociodemographic antecedents. Three decades ago, Lithuania was undergoing massive socioeconomic changes and, as a result, transformed from an impoverished to a high-income country (World Bank, 2021). Since 2015, the IMF classified the country as one of the advanced economies (International Monetary Fund, 2018). Rapid economic growth and the relatively short path to affluence provide a unique context for materialism research. As indicated by a wide-scale representative study by Twenge and Kasser (2013), impoverished economic conditions during one's childhood have a lagging effect on youth's heightened materialism later in life. Researchers conclude that economic deprivation during childhood predicts higher levels of materialism ten years later. Notably, it is plausible to suggest that those lagging effects may be of particular relevance to the materialistic dispositions of Lithuanian consumers. The country faced rapid socioeconomic changes and abandoned economic insecurity in only 25 years, as opposed to the incremental development of Western European countries. The under-researched Eastern European consumer dispositions may provide valuable insights and contribute to materialism literature on the prevalence of materialism and its associations with sociodemographic variables.

Former research produced mixed results on the effects of socioeconomic variables on materialism. For example, the cross-cultural comparison of demographic antecedents with materialistic concerns revealed that men are more materialistic in the Sweden sample, while in Greek and Chilean cases, women scored higher (Cleveland et al., 2009). Lack of consensus regarding gender differences is also observed in more recent materialism studies (Workman \& Lee, 2011; Segal \& Podoshen, 2013; Keech et al., 2020; Jiang et al., 2020). Similarly, research on the impact of age is also inconsistent. For example, the Dutch population's longitudinal representative study (Jaspers \& Pieters, 2016) contradicts the established notion that age negatively affects materialism, providing evidence for the $U$ shape materialism development curve throughout one's lifespan. The lack of agreement across different studies urges the investigation of demographic determinants. The present study addresses the gap discussed above and sheds light on the range of demographic variables that may predict the nature of materialism, whereas most other research in this area has been limited to merely one or two single sociodemographic antecedents, for instance, age (Jaspers \& Pieters, 2016), gender (Segal \& Podoshen, 2013; Keech, Papakroni \& Podoshen, 2020) or income (Chaplin et al., 2014). Although sociodemographic characteristics are informative for developing marketing strategies, their effects in previous studies are confined by assigning them secondary importance - merely control variable function. Furthermore, similar studies are mainly focused on students or adolescent samples (Ger \& Belk, 1996; Kilbourne et al., 2005; Schaefer et al., 2004), whereas the current study reflects a more diverse population of one country by relying on professional online research panel (random stratified sampling) data that represents the Lithuanian adult population. Given the above, this study aims to investigate the relationship between the materialistic values and personal characteristics such as age, gender, income, and education in the Lithuanian population. The results of this research provide twofold contributions. First, we contribute to the literature by providing new insights and broadening scientific knowledge about consumer materialism in a transitional economy country and during the Covid-19 pandemic and lockdown. Second, we contribute to materialism research by demonstrating that vulnerable consumers are more likely to engage in materialistic behavior than more privileged groups. The findings of the study have practical implications for marketers and policymakers concerned with societal well-being.

\section{Literature Review and Hypotheses}

\section{Materialism: Conceptualisation}

Consumer materialism relates to how much consumers value possessions (Belk, 1985). The most commonly accepted definition of materialism is a "set of centrally held beliefs about the importance of possessions in one's life" (Richins \& Dawson, 1992, p. 308). Basing on Kasser (2002), materialism is uniquely identified with consumption that leads to happiness that can be enhanced through possessions.

Materialistic people are attached to possessions that take the important place in their lives. Fitzmaurice and Comegys (2014) state that the continual acquisition of goods becomes a primary goal for materialists. They claim that materialists often become overly fixated on acquiring objects, and, as such, dedicate a major part of their time, energy and resources on purchasing goods.

The literature analysis reveals that scholars have two perspectives on the development of materialistic values in individuals, i.e., the socialisation and the psychological approach. Moschis (2007) argues that both states are related to events that take place at an early age of an individual. $\mathrm{He}$ found that weaker self-esteem and parent-child relationships may increase an individual's vulnerability to stressful events later in life, further promoting an inclination toward materialism. Scholars (Rindfleisch et al., 1997; Roberts et al., 2003; Mochis, 2007) have also revealed that those individuals who experienced certain events (e.g., family disruption events of divorce and separation) during their adolescent years as well as those that were brought up by materialistically oriented parents (Chaplin \& John, 2010) are more prone to materialism and compulsive buying as they feel more stress and insecurity.

The research on materialism is expansive and not yet conclusive. The literature review shows that various authors have conceptualised materialism as a singular construct but have measured it as a multidimensional one. Researchers have developed two approaches on conceptualising materialism. Belk $(1984,1985)$ has proposed three measures of materialistic traits - possessiveness, non-generosity and envy. Belk (1984) has defined possessiveness as "an inclination and tendency to retain control or ownership of one's possessions". The non-generosity involves the unwillingness to give possessions to or share possessions with others (Belk 1985). Belk (1984) emphasised that envy can be treated both ways, i.e., as a benign characteristic that motivates striving to acquire the desired object, and as a destructive characteristic that leads to vandalism, murder, etc. Gilovich et al. (2015) have indicated that this process never ends as the pleasure from the purchase quickly fades away, and the materialists become victims of their own desires and excessive needs. 
Richins and Dawson (1992) have proposed three components to measure value-oriented materialism among individuals. Based on these authors, the more consumers value material remuneration as the essential goal of life, see material possession or its acquisition as the main path to success and happiness, and use material possessions to determine their identity, the more materialistic they are considered to be. This approach encompasses three interrelated domains: centrality, happiness and success (Richins \& Dawson, 1992; Richins 2004). The centrality facet conveys the extent to which consumers believe that acquisition and possession of things is essential to their lives. The success facet of materialism is the belief that one's and other people's success might only be signalled and validated by the evident material wealth and acquisitions. The happiness facet is associated with the belief that possessions and their acquisition is the main route to happiness and satisfaction with life. The value orientation approach, which encompasses the facets of centrality, happiness and success, is predominant in studies of consumer behaviour.

\section{Materialism and Age}

According to Belk (1985), consumers, when they reach an older age, are more mature and have greater contact with purchasing decision processes; consequently, they present a lower predisposition towards materialism. According to O'Guinn and Faber (1989), the average age of compulsive buyers who purchase chronically because of low selfesteem, negative events or feelings, can be as low as 18; this is also supported by Faber and Christenson (1996). Fu et al. (2015) state that the ongoing search for self-identity of these consumers may make them more materialistic. La Barbera and Gurhan (1997) also emphasise that older individuals realise that life is not limited to acquiring possessions. In addition, Martin et al. (2019) indicates that the strength of materialistic value orientations changes with age and that younger consumers are more prone to materialism.

Ditmar (2005b) proposed a two-factor model that, when used among young women, found the ideal-self motivation to have a stronger mediating mechanism for women in their mid-adulthood. This finding suggests that ideal-self buying may constitute a stronger motivation among younger women, or it is more closely linked to their selfdiscrepancies, possibly reflecting a less stable sense of identity or stronger consumer culture socialisation. Commitment to materialism was determined to be a direct predictor of compulsive buying among younger and older women, as well as young men (Ditmar 2005a).

Yurchisin and Johnson (2004) investigated the relationship between compulsive buying and one's perceived social status as it relates to buying, materialistic attitudes, self-esteem, and apparel-product involvement for young adults (18 to 24 years old). According to their findings, this age range is the average onset age of compulsive buying behaviour.

Furthermore, Chan and Prendergast (2008) argue that youth actively engage in advertisement and imitate celebrities, which leads to higher levels of materialism in younger consumers. Young people admire innovative products and, as a result, are more receptive to promotional offers, which in turn causes inclination to materialistic values (Shrum et al., 2013). Martin et al. (2019) claim today's youth to be the most consumption oriented and materialistic generation in history. In addition, youths that willingly engage in social interactions with their peers tend to be more engaged in materialistic lifestyles (Sheldon \& Lyubomirsky, 2004; Li et al., 2018). Lastly, prior research confirms that consumers who grew up in materialistically oriented households are also more prone to develop materialistic inclinations (Chaplin et al., 2014).

A study by Islam et al. (2017) shows that young adults and adolescents are more engaged in social comparison to others, which leads to greater development of materialistic values and compulsive buying. Moreover, young consumers tend to be heavy users of social media that functions as a moderator of social comparison to celebrities and peers. Islam et al. (2018) have also proposed three dominant factors of materialistic values and compulsive buying of young adults: peer groups, media celebrities and TV advertisements. In addition, Ho and Lwin (2019) confirm that the use of social networking sites encourages a higher level of materialism among young consumers. Based on the above, we suggest that:

\section{H1: Younger consumers are more prone to materialism}

\section{Materialism and Gender}

Literature analysis fails to reveal a unanimous answer to the question whether there is a correlation between gender and one's propensity for materialism. Researchers document ambiguous results. One can distinguish a group of empirical studies that do not support any statistically significant differences across gender regarding materialism. A noteworthy study to cite is a 2017 meta-analysis of the antecedent and consequent constructs of materialism by Santini et al. (2017). An overview of 77 articles that examined the question (a cumulative sample of 40.288 studied individuals taken from thirteen database information sources) demonstrated that the relationship is not statistically supported. Similarly, a study in Turkey showed there to be no substantial variance across gender on materialistic attitudes and material satisfaction in the student population (Ozgen \& Esiyok, 2020). Likewise, no significant gender differences were found among the U.S. respondents (Keech et al., 2020).

However, research examining gender differences in materialism and consumption patterns is pervasive and opposite results have been highlighted in the literature. Some authors, such as Eastman et al. (1997) and Kamineni (2005), claim men to exhibit higher levels of materialism than women. Moreover, a study of luxury good consumption of university students in Latin America revealed that men are more inclined to purchase and use new luxury products (Verdugo \& Ponce 2020). Ajitha and Sivakumar (2019) found similar gender differences in an analogous study conducted in India. According to the studies by Goldsmith et al. (2011), material goods were more essential to the happiness of men than women in the United States. Such studies similarly raise questions whether the results related to materialism are an outcome of wealth, gender inequality and different social expectations towards men and women to exploit luxury items as symbols of social status. 
On the opposite end, studies by Lewallen et al. (2016) and Flynn et al. (2013) show that women tend to adhere to materialistic beliefs more than men. It is important to note that such a link is often established on indirect results of other studies, e. g., that women enjoy shopping and are involved in shopping activities more than men (Fischer \& Arnold, 1990; Goldsmith et al., 2011), that materialism can be considered a significant predictor of time spent shopping (Fitzmaurice \& Comegys, 2006), that women are more detail-oriented in processing advertising information (Kruger \& Byker 2009), more likely to be compulsive buyers (Dittmar, 2005a), are more responsive to sales (Kruger \& Byker, 2009; Liao et al., 2009), and so on. Such methodology may fail to take into account social gender norms, as, for example, in many cultures women are expected to do the majority of domestic labour which includes purchasing household goods. On the other hand, Bakir et al. (2020) cite a 2013 study by Stokburger-Sauer and Teichmann, which demonstrated women to have a more positive attitude toward luxury products than men. Such ambiguous results may be an outcome of gender related cultural differences between research participants, variation in methodology, and other significant factors - not excluding the biases vis-a-vis gender held by researchers who choose to pose some questions over others. However, taking this into account, the proposed hypothesis will nonetheless follow the line of previous research conducted in Europe that tends to show women to be more materialistic than men. Therefore, we hypothesise:

\section{H2 Women are more prone to materialism}

\section{Materialism and Income}

The effect of income on materialism has been reported to be inconclusive. Within the low-income sample of Sao Pao households, no association was detected between materialism and income (Ponchio \& Aranha, 2008). Roberts and Clement (2007) discovered that income does not affect the respondents' overall materialism except for the happiness dimension. Researchers conclude that the lesser the income, the more happiness is assumed to be derived from material possessions. Kasser et al. (1995) have found that the disadvantageous socio-economic environment within which adolescents have grown up predicts higher aspiration for financial success. The explanation of this pattern is attributed to the less supportive social environment where fulfilment of extrinsic goals outweighs the value of intrinsic goals. The higher relative emphasis on financial success might be a result of the desire to conform to the values of the community in which realisation of extrinsically rewarded goals enables an individual to feel safer and distance oneself from association with low socioeconomic status perceived as self-worth degrading.

Other studies suggest that materialism is not susceptible to income (Cleveland et al., 2009) and that affluence does not account for materialistic dispositions (Ger \& Belk, 1996). In the same vein, recent research by Kim et al. (2017) revealed that the lack of financial resources per se is not related to heightened materialism. Instead, materialistic aspirations stem from personal relative deprivation. More specifically, as pointed out by Kim et al. (2017), it is a sense of subjective unfairness resulting from social comparison rather than the increase in income inequality that predicts higher levels of materialism.

Numerous studies employing various research designs suggest that poverty and deprived socio-economic conditions stimulate the development of materialistic orientations as a way to compensate for the negative sense of self. Earlier studies evidenced that consumers high in the materialism scale demonstrate heightened desire for income and are less satisfied with their incomes (Richins \& Dawson, 1992). In other studies, similar findings are observed. For example, Goldberg et al. (2003) found that lower household incomes predicted higher youth materialism. Moreover, interviews conducted by Chaplin et al. (2014) have shown that impoverishment increases youth vulnerability to the development of materialistic values. Low self-esteem was suggested as a mediator accounting for the higher levels of materialism of low-income teens. Furthermore, findings of experimental studies by Li et al. (2018) also confirm that in the short run social class (which also encompasses family income) has a negative impact on materialistic tendencies, which occur as compensation for self-esteem. Consequently, we propose that:

H3 Consumers of low self-perceived relative income are more prone to materialism

\section{Materialism and Education}

Relatively few studies that analyse the correlation between education and materialism can be found. However, when discussing factors that have influence on materialism, it is important to evaluate, among others, the educational factor. The role of education in materialism has not been extensively explored, but this variable may be important when modelling the links between materialism and emotional intelligence, subjective well-being and compulsive buying.

It must be noted that the educational factor in materialism may be multifaceted: it may be oriented towards education level, academic achievement, skills acquired during learning, and it may include education of parents, and the like. Scientists are interested in the role of materialism in the process of education. There are scientific works that analyse the correlation between materialism and academic achievement of young people (Froh et al., 2011; Goldberg et al., 2003; Ku et al., 2014). These studies identify materialism as a predictor for weaker academic achievement among adolescents, as well as lower levels of mastery goal pursuit and higher levels of performance goal pursuit. Other authors maintain that materialism has a negative correlation with key indicators of learning. Students with high materialistic predispositions tend to be less engaged and are less successful academically, with such links partially mediated by motivation (King \& Datu 2017). Thus, "materialistic values were not only negatively associated with teen-agers' mastery-oriented learning motivation, but also resulted in deterioration of school grades over time" (Ku et al., 2014, p. 84).

When trying to find out whether correlation between materialism and education level exists, ambiguous results are also obtained. Some studies have established that of all demographic variables, only the level of education is relevant to materialism, with gender, age and status of activity having a markedly less significant impact (Hofmeister \& Neulinger, 
2013). However, other researchers find that education has no impact on materialism (Parashar \& Jain, 2017; Roberts \& Clement, 2007).

When interpreting how materialism is related to one's education level, some researchers claim that more educated subjects are more inclined towards materialism than their less educated counterparts. Those who have a degree, or a diploma are significantly more materialistic than those without (Mandy, 2018). Additionally, post graduate respondents have been found to be more materialistic than undergraduates (Parashar \& Jain, 2017). The possible direct relation between materialism and education may be explained by the expectation of socioeconomic status of individuals with higher education. However, other studies reveal the opposite: people with higher education exhibit lower levels of materialism as compared to elementary grade students (Hofmeister \& Neulinger, 2013; Micken, 1993). In their study, Dogan and Torlak (2014) establish that the perceived significance of money is statistically different in groups of subjects with high and low education. The said scholars assert that the less educated participants were more disposed to see money as a source of worry and security for an indefinite future, whereas participants with a higher level of education may hold on to different attitudes more in line with the sense of security provided by their careers (Dogan \& Torlak, 2014). Hence it may be assumed that materialism of individuals with lower education may arise from their state of insecurity and worry about basic survival.

When analysing the correlation between materialism and education, some studies consider the background of the subjects, i.e., economic status and education of their parents. Diverging academic opinions abound in this case as well, with some researchers maintaining that children of parents with higher education tend to be more materialistic (ErsoyQuadir, 2012), and others claiming that individuals from less educated and poorer families feel insecurity that leads to a more likely acceptance of materialistic values compared to those who come from wealthier and more educated families (Flouri, 2004). Although discussions about the relation between education and materialism persist, results show that the idea that people with a higher education care less about materialistic values would fit into the cultural context of Lithuania better. Thus, we hypothesise that:

H4 People with a higher education level are less materialistic

\section{Research Methodology}

\section{Measures}

Based on the literature and expert representations of materialism, an individual with highly materialistic values believes that the acquisition of material goods is a central life goal, the primary indicator of success, and the key to happiness and self-definition (Dittmar, 2005a, p. 472; Richins, 2004). To measure materialism, we used Materialistic Values Scale (MVS) provided by Richins (2004), which is the most widely used and psychometrically validated scale measure of materialism in consumer research (Wong et al., 2003, p. 74). The present study utilises nine items from the Richins and Dawson materialism scale (Richins and Dawson, 2004), with three measures for each of the factors (success, centrality and happiness) that comprise materialism. For example, item "I would be happier if I could afford to buy more things" was used to measure "happiness", item "buying things gives me a lot of pleasure" was used to measure "central life goal", and item "some of the most important achievements in life include acquiring material possessions" was used to measure "success". All items were included in the questionnaire and presented in a random order rather than blocked by subscale and were measured with five-point Likert-type scales from 1 being "strongly disagree" to 5 being "strongly agree".

\section{Data Collection and Survey Instrument}

In this study, a survey questionnaire has been developed by all authors using the insights obtained from the relevant literature. The draft version of the survey was then pretested by 20 researchers and individuals and their feedback and comments were used to improve the final version of the survey. The survey was then distributed in the digital form among individuals over 18 years old living in Lithuania.

This study relies on a professional online research panel and uses computer assisted web interview (CAWI) method to gather the data, while using a pre-screening methodology for respondents' attentiveness. The stratified random sampling procedure was used, and the strata were defined in terms of age (18-65) and gender (woman and man). The data was collected between November-December 2020. In order to assure respondents that their personal information will be used only for the purpose of the current study, we informed them that the collected data would remain anonymous and will be analysed for research purposes only at an aggregate level.

The invitation link was sent to 2340 individuals, and $1226(52 \%)$ of the recipients started the survey, but only 1000 completed the survey. Therefore, the response rate based on the respondents who received the invitation is approximately $(42.7 \%)$.

Moreover, we collected measures for different constructs from different sources. This approach allowed us to control the potential common method bias (Chang et al., 2010, p. 179). Moreover, the non-response bias was assessed through the $t$-test and we compared the average scores for the main variables of the first $20 \%$ of the respondents and the last $20 \%$ of the respondents, as recommended by Lau et al. (2010). We did not find any significant differences between the mean scores of the two groups. Following that, we examined the non-response bias test based on the respondents' age and gender, and no major differences between the responding and non-responding respondents were found. We conducted a two-tailed test to check whether the two proportions (initial sample and effective sample) are equal. According to the $\mathrm{Z}$ scores, the proportions of the two samples do not differ significantly with respect to all demographic characteristics. The findings provide evidence suggesting that there are no significant differences between the proportions of the total sample and effective sample, which excludes missing values. 
Dalia Antiniene, Beata Seinauskiene, Ausra Rutelione, Shahrokh Nikou, Rosita Lekaviciene. Do Demographics Matter...

\section{Results}

\section{Descriptive Statistics}

Of 1000 respondents, $506(50.6 \%)$ were women and $494(49.4 \%)$ were men. In order to effectively explore gender differences, we adjusted our sample to not overrepresent women. The age of respondents ranged from 18 to 65 years old with an average age of $\left(\mathrm{M}_{\text {age }}=42.12\right.$ years; $\mathrm{SD}$ $=13.22$ ). The respondents were within the age ranges of age 18-24 $(\mathrm{N}=125)$, age $25-34(\mathrm{~N}=216)$, age $35-44(\mathrm{~N}=193)$, age 45-54 $(\mathrm{N}=227)$ and age $55-65(\mathrm{~N}=239)$. The majority of the respondents $(\mathrm{N}=506)$ mentioned that they have a higher education (university) degree, and 143 reported that they have either primary or secondary education, and 20 respondents mentioned they had primary education, see Table 1. We also asked respondents to indicate their perceptions about their financial living situation and more than half of the respondents responded that they live like most Lithuanian people. When respondents were asked to indicate their preference of shopping place, only 242 mentioned they prefer online stores, whereas the rest indicated physical stores as their preferred shopping place.

Demographic Information of the Respondents

\begin{tabular}{|c|c|c|}
\hline Gender & Frequency & Percentage \\
\hline Man & 494 & 49.2 \\
\hline Woman & 506 & 50.8 \\
\hline \multicolumn{3}{|c|}{ Age } \\
\hline $18-24$ & 125 & 12.5 \\
\hline $25-34$ & 216 & 21.6 \\
\hline $35-44$ & 193 & 19.3 \\
\hline $45-54$ & 227 & 22.7 \\
\hline $55-65$ & 239 & 23.9 \\
\hline \multicolumn{3}{|c|}{ Place of purchase } \\
\hline I prefer shopping in a physical store & 758 & 75.8 \\
\hline I prefer shopping in an online store & 242 & 24.2 \\
\hline \multicolumn{3}{|c|}{ Education } \\
\hline Primary & 20 & 2 \\
\hline Secondary & 123 & 12.3 \\
\hline Higher / special secondary & 162 & 16.2 \\
\hline Unfinished higher & 47 & 4.7 \\
\hline Higher (non-university) & 142 & 14.2 \\
\hline Higher (university) & 506 & 50.6 \\
\hline \multicolumn{3}{|c|}{ You think that financially you live } \\
\hline Significantly worse than most Lithuanian people & 16 & 1.6 \\
\hline Worse than most Lithuanian people & 77 & 7.7 \\
\hline Like most Lithuanian people & 585 & 58.5 \\
\hline Slightly better than most Lithuanian people & 268 & 26.8 \\
\hline Significantly better than most Lithuanian people & 54 & 5.4 \\
\hline
\end{tabular}

A preliminary analysis of the scale items, consisting of two factor analyses, was performed (see Table 2). The first was an exploratory factor analysis (EFA) and the second was a confirmatory factor analysis (CFA). Factor loadings below .3 were suppressed (Dittmar, 2005a, p. 474). All MVS items loaded on their respective subscales factor, except two items that showed low cross-loadings compared to the acceptable level of .70. The fact that they were

\section{Descriptive Statistics of Scale Measure of Materialism}

\begin{tabular}{|c|l|c|c|c|}
\hline Construct & \multicolumn{1}{|c|}{ Items } & Factor loading & Mean & Std. \\
\hline \multirow{2}{*}{$\begin{array}{l}\text { Materialism } \\
\text { Centrality) }\end{array}$} & I enjoy spending money on things that are not that practical & 0.689 & 2.29 & 0.93 \\
\cline { 2 - 5 } & Buying things gives me a lot of pleasure & 0.737 & 3.15 & 0.99 \\
\cline { 2 - 5 } & I like a lot of luxury in my life & 0.786 & 3.03 & 1.07 \\
\hline & My life would be better if I owned certain things, I do not have & 0.838 & 2.84 & 1.02 \\
\hline
\end{tabular}


Inzinerine Ekonomika-Engineering Economics, 2021, 32(4), 296-312

\begin{tabular}{|c|c|c|c|c|}
\hline Construct & Items & Factor loading & Mean & Std. \\
\hline \multirow{2}{*}{$\begin{array}{l}\text { Materialism } \\
\text { (Happiness) }\end{array}$} & I would be happier if I could afford to buy more things & 0.837 & 3.41 & 0.96 \\
\hline & $\begin{array}{l}\text { It sometimes bothers me quite a bit that I cannot afford to buy all the things } \\
\text { I would like }\end{array}$ & 0.808 & 2.95 & 1.06 \\
\hline \multirow{3}{*}{$\begin{array}{l}\text { Materialism } \\
\text { (Success) }\end{array}$} & I admire people who own expensive homes, cars, and clothes & 0.775 & 2.70 & 1.08 \\
\hline & $\begin{array}{l}\text { I think that some of the most important achievements in life include } \\
\text { acquiring material possessions }\end{array}$ & 0.691 & 2.70 & 1.05 \\
\hline & I like to own things that impress people & 0.789 & 2.24 & 0.96 \\
\hline
\end{tabular}

In the next step, we examined how different factors influence consumers' materialistic behaviour taking into consideration individual characteristics such as age, gender, income and education. Regarding age and how different age groups affect the materialistic disposition of Lithuanians, significant differences were found in all nine measures of materialism (see Table 3) with younger consumers age $=18-24$ scoring "more materialistic". Given that younger consumers scored higher than other age groups in all items, we conclude that $\mathrm{H} 1$ is supported.

Table 3

Differences in Materialism (Age Group) of Lithuanian Respondents

\begin{tabular}{|c|c|c|c|c|c|}
\hline Measures & Age group & Mean & Std. & F-statistic & Sig \\
\hline \multirow{5}{*}{ MATC1 } & $18-24$ & 2.56 & 0.99 & \multirow{5}{*}{$\mathrm{F}(4.992)=5.909$} & \multirow{5}{*}{0.001} \\
\hline & $25-34$ & 2.37 & 1.01 & & \\
\hline & $35-44$ & 2.23 & 0.87 & & \\
\hline & $45-54$ & 2.31 & 0.90 & & \\
\hline & $55-65$ & 2.1 & 0.88 & & \\
\hline \multirow{5}{*}{ MATC2 } & $18-24$ & 3.44 & 1.03 & \multirow{5}{*}{$F(4.992)=3.822$} & \multirow{5}{*}{0.004} \\
\hline & $25-34$ & 3.18 & 1.03 & & \\
\hline & $35-44$ & 3.03 & 1.03 & & \\
\hline & 45-54 & 3.12 & 0.95 & & \\
\hline & 55-65 & 3.07 & 0.95 & & \\
\hline \multirow{5}{*}{ MATC3 } & $18-24$ & 3.18 & 1.10 & \multirow{5}{*}{$\mathrm{F}(4.992)=2.707$} & \multirow{5}{*}{0.029} \\
\hline & $25-34$ & 3.16 & 1.12 & & \\
\hline & $35-44$ & 3.06 & 1.07 & & \\
\hline & $45-54$ & 2.98 & 1.01 & & \\
\hline & $55-65$ & 2.87 & 1.07 & & \\
\hline \multirow{5}{*}{ MATH1 } & $18-24$ & 3.19 & 1.07 & \multirow{5}{*}{$\mathrm{F}(4.992)=9.107$} & \multirow{5}{*}{0.001} \\
\hline & $25-34$ & 3.01 & 1.07 & & \\
\hline & $35-44$ & 2.83 & 1.00 & & \\
\hline & $45-54$ & 2.72 & 0.98 & & \\
\hline & 55-65 & 2.62 & 0.94 & & \\
\hline \multirow{5}{*}{ MATH2 } & 18-24 & 3.47 & 0.94 & \multirow{5}{*}{$F(4.992)=4.11$} & \multirow{5}{*}{0.003} \\
\hline & $25-34$ & 3.6 & 0.94 & & \\
\hline & $35-44$ & 3.3 & 1.00 & & \\
\hline & 45-54 & 3.44 & 0.92 & & \\
\hline & $55-65$ & 3.27 & 0.96 & & \\
\hline \multirow{5}{*}{ МАTH3 } & $18-24$ & 3.3 & 1.04 & \multirow{5}{*}{$\mathrm{F}(4.992)=13.52$} & \multirow{5}{*}{0.001} \\
\hline & $25-34$ & 3.22 & 1.09 & & \\
\hline & $35-44$ & 2.78 & 1.01 & & \\
\hline & 45-54 & 2.95 & 1.05 & & \\
\hline & 55-65 & 2.66 & 0.99 & & \\
\hline \multirow{5}{*}{ MATS1 } & 18-24 & 3.07 & 1.05 & \multirow{5}{*}{$F(4.992)=12.691$} & \multirow{5}{*}{0.001} \\
\hline & $25-34$ & 2.96 & 1.10 & & \\
\hline & $35-44$ & 2.73 & 1.05 & & \\
\hline & $45-54$ & 2.72 & 1.10 & & \\
\hline & $55-65$ & 2.37 & 0.99 & & \\
\hline MATS2 & 18-24 & 3.02 & 1.02 & $\mathrm{~F}(4.992)=6.879$ & 0.001 \\
\hline
\end{tabular}


Dalia Antiniene, Beata Seinauskiene, Ausra Rutelione, Shahrokh Nikou, Rosita Lekaviciene. Do Demographics Matter...

\begin{tabular}{|c|c|c|c|c|c|}
\hline Measures & Age group & Mean & Std. & F- statistic & Sig \\
\hline & $25-34$ & 2.83 & 1.12 & & \\
\hline & $35-44$ & 2.66 & 1.01 & & \\
\hline & $45-54$ & 2.69 & 1.05 & & \\
\hline & $55-65$ & 2.46 & 1.00 & & \\
\hline \multirow{5}{*}{ MATS3 } & $18-24$ & 2.46 & 1.02 & \multirow{5}{*}{$F(4.992)=5.909$} & \multirow{5}{*}{0.001} \\
\hline & $25-34$ & 2.28 & 1.04 & & \\
\hline & $35-44$ & 2.29 & 0.95 & & \\
\hline & $45-54$ & 2.25 & 0.91 & & \\
\hline & $55-65$ & 2.01 & 0.87 & & \\
\hline
\end{tabular}

Moreover, ANOVA in SPSS version 26 was performed between the two gender groups and Table 4 shows significant differences in five out of the nine materialism measures when comparing Lithuanian women to men at an alpha level of .05. Significant differences were found in one of the three centrality measures, two of the three happiness measures and two of the three success measures with women scoring "more materialistic" in four of the significant measures. Given that women scored higher than men in the majority of scale items and according to the results of mean effect size difference using the "Cohen's $d$ " test results for both groups, we conclude that $\mathrm{H} 2$ is supported.

Table 4

Differences in Materialism (Women vs. Men) of Lithuanian Respondents

\begin{tabular}{|c|c|c|c|c|c|c|}
\hline Measures & Gender & Mean & Std. & F-statistic & Cohen's $d$ & Sig \\
\hline \multirow{2}{*}{ MATC1 } & Female & 2.32 & 0.975 & \multirow{2}{*}{$F(1.995)=0.794$} & \multirow{2}{*}{0.06} & \multirow{2}{*}{ NS } \\
\hline & Male & 2.26 & 0.892 & & & \\
\hline \multirow{2}{*}{ MATC2 } & Female & 2.97 & 0.987 & \multirow{2}{*}{$F(1.995)=29.532$} & \multirow{2}{*}{-0.34} & \multirow{2}{*}{0.001} \\
\hline & Male & 3.31 & 0.978 & & & \\
\hline \multirow{2}{*}{ MATC3 } & Female & 3.01 & 1.085 & \multirow{2}{*}{$F(1.995)=0.332$} & \multirow{2}{*}{-0.04} & \multirow{2}{*}{ NS } \\
\hline & Male & 3.05 & 1.064 & & & \\
\hline \multirow{2}{*}{ MATH1 } & Female & 2.96 & 1.012 & \multirow{2}{*}{$F(1.995)=13.255$} & \multirow{2}{*}{0.23} & \multirow{2}{*}{0.001} \\
\hline & Male & 2.73 & 1.014 & & & \\
\hline \multirow{2}{*}{ MATH2 } & Female & 3.48 & 0.924 & \multirow{2}{*}{$F(1.995)=5.252$} & \multirow{2}{*}{0.15} & \multirow{2}{*}{0.022} \\
\hline & Male & 3.34 & 0.983 & & & \\
\hline \multirow{2}{*}{ MATH3 } & Female & 2.99 & 1.059 & \multirow{2}{*}{$F(1.995)=1.439$} & \multirow{2}{*}{0.08} & \multirow{2}{*}{ NS } \\
\hline & Male & 2.91 & 1.062 & & & \\
\hline \multirow{2}{*}{ MATS1 } & Female & 2.81 & 1.085 & \multirow{2}{*}{$F(1.995)=4.839$} & \multirow{2}{*}{0.14} & \multirow{2}{*}{0.028} \\
\hline & Male & 2.66 & 1.072 & & & \\
\hline \multirow{2}{*}{ MATS2 } & Female & 2.74 & 1.035 & \multirow{2}{*}{$\mathrm{F}(1.995)=1.711$} & \multirow{2}{*}{0.08} & \multirow{2}{*}{ NS } \\
\hline & Male & 2.66 & 1.068 & & & \\
\hline \multirow{2}{*}{ MATS3 } & Female & 2.36 & 1.015 & \multirow{2}{*}{$F(1.995)=16.655$} & \multirow{2}{*}{0.26} & \multirow{2}{*}{0.001} \\
\hline & Male & 2.11 & 0.882 & & & \\
\hline
\end{tabular}

Note: Female $(\mathrm{N}=491)$; Male $(\mathrm{N}=506)$; Significance at $p<0.05$

Regarding consumers' self-perceived relative income, we postulated that consumers with low income are more prone to materialism. As shown in Table 5, Lithuanian consumers with low income scored higher than the other four groups. Significant differences were found in one of the three centrality measures, two of the three happiness measures and two of the three success measures with Group 1 low-income scoring "more materialistic" in five of the significant measures. Given that Lithuanian consumers with low income scored higher than the other four groups, we conclude that $\mathrm{H} 3$ is supported.

Differences in Materialism (Income) of Lithuanian Respondents

Table 5

Droups

\begin{tabular}{|c|l|c|c|c|c|}
\hline Measures & Groups & Mean & Std. & F-statistic & Sig \\
\hline \multirow{3}{*}{ MATC1 } & Low income & 2.81 & 1.38 & & \multirow{2}{*}{ F(4. 992)=1.814 } \\
\cline { 2 - 4 } & G 2 & 2.18 & 1.01 & 0.124 \\
\cline { 2 - 4 } & G 3 & 2.31 & 0.91 & & \\
\cline { 2 - 4 } & G 4 & 2.25 & 0.92 & & \\
\hline
\end{tabular}




\begin{tabular}{|c|c|c|c|c|c|}
\hline Measures & Groups & Mean & Std. & F-statistic & Sig \\
\hline & High income & 2.39 & 0.96 & & \\
\hline \multirow{5}{*}{ MATC2 } & Low income & 2.81 & 1.17 & \multirow{5}{*}{$F(4.992)=2.044$} & \multirow{5}{*}{0.086} \\
\hline & G 2 & 2.91 & 1.08 & & \\
\hline & G 3 & 3.19 & 0.96 & & \\
\hline & G 4 & 3.16 & 0.98 & & \\
\hline & High income & 3.06 & 1.25 & & \\
\hline \multirow{5}{*}{ MATC3 } & Low income & 3.41 & 1.37 & \multirow{5}{*}{$F(4.992)=4.749$} & \multirow{5}{*}{0.001} \\
\hline & G 2 & 2.86 & 1.20 & & \\
\hline & G 3 & 2.94 & 1.04 & & \\
\hline & G 4 & 3.19 & 1.06 & & \\
\hline & High income & 3.01 & 1.07 & & \\
\hline \multirow{5}{*}{ MATH1 } & Low income & 2.94 & 1.48 & \multirow{5}{*}{$F(4.992)=1.655$} & \multirow{5}{*}{0.158} \\
\hline & G 2 & 3.01 & 1.03 & & \\
\hline & G 3 & 2.87 & 0.98 & & \\
\hline & G 4 & 2.75 & 1.05 & & \\
\hline & High income & 2.67 & 1.15 & & \\
\hline \multirow{5}{*}{ MATH2 } & Low income & 3.75 & 1.34 & \multirow{5}{*}{$F(4.992)=2.845$} & \multirow{5}{*}{0.023} \\
\hline & G 2 & 3.56 & 0.85 & & \\
\hline & G 3 & 3.44 & 0.94 & & \\
\hline & G 4 & 3.32 & 0.95 & & \\
\hline & High income & 3.13 & 1.15 & & \\
\hline \multirow{5}{*}{ MATH3 } & Low income & 3.56 & 1.55 & \multirow{5}{*}{$F(4.992)=4.593$} & \multirow{5}{*}{0.001} \\
\hline & G 2 & 3.19 & 1.04 & & \\
\hline & G 3 & 2.99 & 1.01 & & \\
\hline & G 4 & 2.82 & 1.10 & & \\
\hline & High income & 2.67 & 1.15 & & \\
\hline \multirow{5}{*}{ MATS1 } & Low income & 3.11 & 1.27 & \multirow{5}{*}{$F(4.992)=2.464$} & \multirow{5}{*}{0.044} \\
\hline & G 2 & 3.05 & 1.12 & & \\
\hline & G 3 & 2.68 & 1.04 & & \\
\hline & G 4 & 2.73 & 1.14 & & \\
\hline & High income & 2.83 & 1.11 & & \\
\hline \multirow{5}{*}{ MATS2 } & Low income & 3.31 & 1.30 & \multirow{5}{*}{$F(4.992)=2.312$} & \multirow{5}{*}{0.05} \\
\hline & G 2 & 2.86 & 1.11 & & \\
\hline & G 3 & 2.64 & 1.01 & & \\
\hline & G 4 & 2.73 & 1.10 & & \\
\hline & High income & 2.76 & 1.12 & & \\
\hline \multirow{5}{*}{ MATS3 } & Low income & 2.51 & 1.32 & \multirow{5}{*}{$F(4.992)=1.744$} & \multirow{5}{*}{0.138} \\
\hline & G 2 & 2.09 & 0.95 & & \\
\hline & G 3 & 2.21 & 0.93 & & \\
\hline & G 4 & 2.31 & 0.99 & & \\
\hline & High income & 2.39 & 1.02 & & \\
\hline
\end{tabular}

Note: Significance at $p<0.05$; Low income = Significantly worse than most Lithuanian people; G $2=$ Worse than most Lithuanian people; G $3=$ Like most Lithuanian people; G 4 = Slightly better than most Lithuanian people; High income = Significantly better than most Lithuanian people

Finally, regarding respondents' education, we postulated that people with higher education are less prone to materialism. As shown in Table 6, respondents with higher level education (university degree) scored lower than the other two groups (Group 1 Basic education $(\mathrm{N}=352)$ and Group 2 Higher education non-university degree $(\mathrm{N}=142)$. Significant differences were found in all of the three happiness measures and two of the three success measures with Group 3 Higher education with university degree $(\mathrm{N}=506)$ scoring "less materialistic" in all of the significant measures. Given that Lithuanian consumers with higher education (university degree) scored lower than the other two groups, we conclude that $\mathrm{H} 4$ is supported. 
Dalia Antiniene, Beata Seinauskiene, Ausra Rutelione, Shahrokh Nikou, Rosita Lekaviciene. Do Demographics Matter...

Differences in Materialism (Education Level) of Lithuanian Respondents

\begin{tabular}{|c|c|c|c|c|c|}
\hline Measures & Groups & Mean & Std. & F-Statistic & Sig \\
\hline \multirow{3}{*}{ MATC1 } & Group 1 & 2.37 & 0.97 & \multirow{3}{*}{$\mathrm{F}(2.994)=2.22$} & \multirow{3}{*}{0.109} \\
\hline & Group 2 & 2.27 & 0.94 & & \\
\hline & Group 3 & 2.23 & 0.91 & & \\
\hline \multirow{3}{*}{ MATC2 } & Group 1 & 3.15 & 1.04 & \multirow{3}{*}{$F(2.994)=0.063$} & \multirow{3}{*}{0.939} \\
\hline & Group 2 & 3.17 & 1.06 & & \\
\hline & Group 3 & 3.11 & 0.95 & & \\
\hline \multirow{3}{*}{ MATC3 } & Group 1 & 3.11 & 1.09 & \multirow{3}{*}{$F(2.994)=1.159$} & \multirow{3}{*}{0.314} \\
\hline & Group 2 & 2.94 & 1.15 & & \\
\hline & Group 3 & 3.08 & 1.04 & & \\
\hline \multirow{3}{*}{ MATH1 } & Group 1 & 2.93 & 1.02 & \multirow{3}{*}{$F(2.994)=3.808$} & \multirow{3}{*}{0.023} \\
\hline & Group 2 & 2.92 & 1.12 & & \\
\hline & Group 3 & 2.75 & 0.98 & & \\
\hline \multirow{3}{*}{ MATH2 } & Group 1 & 3.5 & 0.93 & \multirow{3}{*}{$F(2.994)=5.228$} & \multirow{3}{*}{0.006} \\
\hline & Group 2 & 3.52 & 1.00 & & \\
\hline & Group 3 & 3.31 & 0.96 & & \\
\hline \multirow{3}{*}{ MATH3 } & Group 1 & 3.06 & 1.06 & \multirow{3}{*}{$F(2.994)=4.054$} & \multirow{3}{*}{0.018} \\
\hline & Group 2 & 3.01 & 1.09 & & \\
\hline & Group 3 & 2.86 & 1.05 & & \\
\hline \multirow{3}{*}{ MATS1 } & Group 1 & 2.89 & 1.10 & \multirow{3}{*}{$F(2.994)=7.263$} & \multirow{3}{*}{0.001} \\
\hline & Group 2 & 2.77 & 1.14 & & \\
\hline & Group 3 & 2.61 & 1.04 & & \\
\hline \multirow{3}{*}{ MATS2 } & Group 1 & 2.83 & 1.03 & \multirow{3}{*}{$F(2.994)=4.975$} & \multirow{3}{*}{0.007} \\
\hline & Group 2 & 2.75 & 1.09 & & \\
\hline & Group 3 & 2.61 & 1.05 & & \\
\hline \multirow{3}{*}{ MATS3 } & Group 1 & 2.31 & 0.98 & \multirow{3}{*}{$F(2.994)=2.196$} & \multirow{3}{*}{0.112} \\
\hline & Group 2 & 2.27 & 0.91 & & \\
\hline & Group 3 & 2.17 & 0.96 & & \\
\hline
\end{tabular}

Note: Group 1 = Basic education $(\mathrm{N}=352)$; Group 2 = Higher education non-university degree $(\mathrm{N}=142)$; Group 3 = Higher education with university degree $(\mathrm{N}=506)$

We further expanded our analysis and performed linear regression analysis. As shown in Table 7, all four demographic variables contribute to materialistic dispositions, providing statistical supports for our hypotheses. For example, we found that less educated subjects are more inclined towards materialism when compared with more educated ones $(\beta=-0.136 ; t=-4.341$; $p<0.01$. We also found that women are more prone to materialism $(\beta=-0.083 ; t=-2.612 ; p<0.001)$ than their male counterparts.

Table 7

Regression Analysis Results

\begin{tabular}{|l|c|c|c|c|c|}
\hline \multicolumn{1}{|c|}{ Regression } & $\boldsymbol{\beta}$ & $\boldsymbol{t}$-statistic & Sig. & $\mathbf{R}^{\mathbf{2}}$ & Hypothesis \\
\hline Age $\rightarrow$ Materialism & -0.231 & -7.471 & 0.001 & 0.052 & H1: Supported \\
\hline Gender $\rightarrow$ Materialism & -0.083 & -2.612 & 0.009 & 0.006 & H2: Supported \\
\hline Income $\rightarrow$ Materialism & -0.072 & -2.285 & 0.023 & 0.004 & H3: Supported \\
\hline Education $\rightarrow$ Materialism & -0.136 & -4.341 & 0.001 & 0.018 & H4: Supported \\
\hline
\end{tabular}

\section{Discussion}

Our results show that material possession and wealth occupy a central place in lives of about $62 \%$ Lithuanians. More than half $(54,6 \%)$ of respondents believe that their success is judged on material possessions. Our study also indicates that $69.3 \%$ of respondents view possessions and their acquisition as conducive to their happiness and satisfaction with life.
However, overall our study showed that on average (Mean $=2.83$, on the five-point Likert type scale), the degree of materialism is somewhat moderate (located around the point of "neither agree nor disagree" on statements) among Lithuanian consumers. It is worth mentioning that prior research of Liobikiene et al. (2020) revealed a relatively high level of materialism (Mean $=3.55$, on a four-point Likert type scale) of Lithuanian citizens in the year 2013. Materialism 
operationalisation in the current study was based on the Richins and Dawson (1992) scale. The earlier study measured materialism as the value placed on wealth, safety, and life achievements. Although the two studies are not directly comparable due to the inconsistencies in measurement approaches, the findings' differences are stimulating further considerations. Our study was conducted during the Covid19 pandemic and lockdown; thus, the prevalence of materialism is presumably reflecting the changing consumer behavioural patterns. Some recent studies relying on Chinese consumers' samples revealed that materialism is positively associated with death threats (Song et al., 2020). The tendency to hoard material resources is explained as the response to the death threat-related anxiety. Similarly, Li et al. ((2020) found that the pandemic's severity is positively related to the degree of materialism.

Initially, the fear and uncertainty caused by Covid-19 lead to panic and hoarding buying behaviour (Usher et al., 2020). However, the value-based materialism conceptualisation has little in common with the preoccupation with such material objects as food and essentials. The latter is hardly relevant in signalling one's status or fulfilling one's need for success or happiness. According to the terror management theory, "The urge to splurge" may be driven by the mortality salience (Arndt et al., 2004). Such materialistic desires have long been associated with the symbolic meaning culturally ascribed to consumption, which helps to assert one's or others' worth. Where acquisitions and possessions before the pandemic were regarded as the signs of affluence, success, and happiness, currently such materialistic objects have lost their effectiveness in providing the base for comparison after governmental bodies imposed social isolation. The offline shopping pleasure was taken away, and the conditions under which consumers were able to signal their identity and communicate their superiority to others have suddenly disappeared. Presumably, the judgment about one's or others success, status, or happiness based on possessions lost its meaning under the circumstances of social isolation and distance. It may also be that facing their mortality consumers re-evaluate the purpose of materialistic aspirations, emphasising the intrinsic values that may seem to be more viable in coping with pandemic-related anxiety.

Among the respondents, younger consumers were found to be more inclined to materialism. Most of the research in other countries reports similar results (Yurchisin \& Johnson, 2004; Roberts et al., 2008; Islam et al., 2018; Ho \& Lwin, 2019; Tarka, 2020). This may be due to the fact that younger consumers still face self-discrepancies and search for self-identity (Ditmar, 2005). Furthermore, youth are more engaged in advertising and promotional offers, especially when it appears on social media and is proposed by celebrities, which in turn increases their compulsive purchases. Their behaviour could also be explained through the fact that younger people tend to be more reliant on social interactions with peers ( $\mathrm{Li}$ et al. 2018), who are relatively more invested in consumer culture than the older generations (La Barbera \& Gurhan 1997; Islam et al., 2017).

Research suggests materialistic tendencies to be linked with gender (Belk, 1984; Manchanda, 2013; Ryan \& Dziurawiec, 2001), but such research findings are inconclusive. The present study results confirmed the proposed hypothesis that women are more prone to materialism than men. Analogous results that conclude women to be more materialistic were obtained by Workman and Lee (2011), Flynn et al. (2013), Grotts and Johnson (2013), Lewallen et al. (2016), and other authors. However, it must be acknowledged that such results cannot be generalised across different cultures; in the context of materialism, gender is a highly culturally sensitive factor. In future research, it should be imperative to formulate hypotheses by specifically naming the culture or region in which the research is conducted (e.g., Keech et al., 2020). This would allow for more accurate comparative intercultural studies in assessing the links between gender and a group's propensity for materialism. At the same time, there is an additional factor that can have a significant impact on the results obtained in terms of gender differences - the age of the subjects. Research indicates that the propensity of men and women to materialism can vary greatly with age, depending on the personal values that the subjects are developing, and gender does not necessarily influence this (Jiang et al., 2020). In summary, research on the relationship between gender and one's propensity for materialism must be construed as a complex study.

As predicted, the income variable relates negatively to materialism measures in the sample of Lithuanian consumers. The current findings show that consumers with lower selfperceived relative income ascribe higher importance to materialistic values. The pattern of a negative effect of income on materialism is consistent with previous findings (Goldberg et al., 2003; Chaplin et al., 2014). Income in the present study was measured as perceived and as relative to the majority of other individuals. Such an approach responds to the stance that only under the condition of comparison with other individuals' financial state can income have predictive power. Therefore, current findings corroborate the conclusion recently proposed by Kim et al., (2017) that it is a personal relative financial deprivation that triggers materialistic orientations. Our findings also echo other studies on the effect of socioeconomic status (which includes income as one of the representing components) on materialism. For example, low socioeconomic status accelerates the increase in materialism (Jiang et al., 2020). Given the adverse relationship between materialism and life satisfaction (Dittmar et al., 2014), the negative effect of income on materialism might be due to the greater importance of relative income as opposed to objective income on life satisfaction (Schalembier et al., 2020).

As it has been mentioned in the literature review section, there are few studies analysing the relation between education and materialism, with all the said studies being neither consistent, nor systemic. Some authors maintain that there is no correlation between materialism and education (Roberts \& Clement, 2007), other authors find positive (Mandy, 2018), still other - negative (Hofmeister \& Neulinger, 2013) correlations. Such diversity of results may hypothetically be explained by cultural specificity of materialism as phenomenon (Ger \& Belk, 1990; Workman \& Lee, 2011), by differences of assessment instruments, and sample volume. In our study, when comparing consumers by education, it appears that more educated individuals, i.e., those with university degrees, are less materialistic. It has to be noted that results obtained in the most recent studies match our results (Hofmeister \& Neulinger, 2013; Yang \& 
Stening, 2016). Especially noteworthy are results obtained by Maison and Adamczyk (2020) in the neighbouring country of Poland; was conducted with a similar sample with regards to the number and age of subjects and arrived at the same conclusion - people with higher education are less inclined towards materialism.

\section{Conclusion}

In terms of materialism, we found that age, gender, income and education impact consumers' materialistic disposition. We found that women score higher than men on materialism, that younger consumers place more weight on materialism and that the possession of higher education level leads to less materialistic behaviour. Finally, we found that respondents who were in the category of less income are more prone to materialism.

Our study provides two relevant theoretical contributions. First, based on our empirical observations, we interpret our results through the lens of materialism, proposing that bridging the gap between demographic information and materialism is a neglected aspect in examining consumer shopping behaviour. Second, we outline factors which, in the light of materialism, influence consumer behaviour and, consequently, the materialistic disposition. Subsequently, based on previous research on materialism, we determine which factors play a particularly relevant role in the materialistic disposition. We do so by showing how different individual characteristics such as gender, age, income and education impact materialistic consumer behaviour.

Our results have some practical implications as well. Marketers, for example, can use the findings because they indicate that personal attributes are the key to consumers' materialistic disposition. On the other hand, the fact that younger, less educated, less financially satisfied consumers and women are more susceptible to materialism, which is harmful to personal and societal well-being, calls for the development of educational policies that lead to attitudinal changes. Education programs that promote the endorsement and reliance on intrinsic goals and aspirations are conducive to personal well-being and are especially relevant for vulnerable consumers. As a result, changes in attitude consistent with sustainability goals may further stimulate more responsible consumption.

\section{Limitations and Further Directions}

The performed study has certain limitations. The data of research were collected in a specific country - Lithuania; therefore, the obtained results cannot be extrapolated to other countries of the world. It would be expedient to perform an analogous study somewhere else, where different cultures towards compulsive buying and materialism may exist, so that validity of results could be confirmed and more comprehensive insights into consumer materialism could be gained. On the other hand, the study has been performed in the specific context of a global pandemic. The said situation has not only changed people's daily habits, but it has also forced many to reassess their values, including materialistic ones. Circumstances of Covid-19 may have had an impact on the results of the study; therefore, it would be informative to repeat the present study when quarantine and other pandemic measures are not in place.

\section{Acknowledgments}

This project has received funding from the Research Council of Lithuania (LMTLT), agreement No. S-MIP-20-12.

\section{References}

Abdeen, A., Rajah, E., \& Gaur, S. S. (2016). Consumers' beliefs about firm's CSR initiatives and their purchase behaviour. Marketing Intelligence \& Planning, 34, 2-18. https://doi.org/10.1108/MIP-06-2014-0107

Ajitha, S., \& Sivakumar, V. J. (2019). The moderating role of age and gender on the attitude towards new luxury fashion brands. Journal of fashion marketing and management, 23, 440-465. https://doi.org/10.1108/JFMM-05-2018-0074

Arndt, J., Solomon, S., Kasser, T., \& Sheldon, K. M. (2004). The urge to splurge: A terror management account of materialism and consumer behavior. Journal of Consumer Psychology, 14(3), 198-212. https://doi.org/10.12 07/s15327663jcp1403_2

Bakir, A., Gentina, E., \& de Araujo Gil, L. (2020). What shapes adolescents' attitudes toward luxury brands? The role of self-worth, self-construal, gender and national culture. Journal of Retailing and Consumer Services, 57, 102208. https://doi.org/10.1016/j.jretconser.2020.102208

Belk, R. W. (1984). Three scales to measure constructs related to materialism: Reliability, validity, and relationships to measures of happiness. ACR North American Advances.

Belk, R. W. (1985). Materialism: Trait aspects of living in the material world. Journal of Consumer research, 12, 265-280. https://doi.org/10.1086/208515

Chan, K., \& Prendergast, G. P. (2008). Social comparison, imitation of celebrity models and materialism among Chinese youth. International Journal of Advertising, 27, 799-826. https://doi.org/10.2501/S026504870808030X

Chang, S. J., Van Witteloostuijn, A., \& Eden, L. (2010). From the editors: Common method variance in international business research. J. Int. Bus. Stud., 41, 178-184. https://doi.org/10.1057/jibs.2009.88

Chaplin, L. N., \& John, D. R. (2010). Interpersonal influences on adolescent materialism: A new look at the role of parents and peers. Journal of Consumer Psychology, 20(2), 176-184. https://doi.org/10.1016/j.jcps.2010.02.002 
Chaplin, L. N., Hill, R. P., \& John, D. R. (2014). Poverty and materialism: A look at impoverished versus affluent children. Journal of Public Policy \& Marketing, 33, 78-92. https://doi.org/10.1509/jppm.13.050

Cleveland, M., Laroche, M., \& Papadopoulos, N. (2009). Cosmopolitanism, consumer ethnocentrism, and materialism: An eight-country study of antecedents and outcomes. J. Int. mark., 17, 116-146. https://doi.org/10.1509/jimk.17.1.116

Dittmar, H. (2005a). Compulsive buying - a growing concern? An examination of gender, age, and endorsement of materialistic values as predictors. Br. J. of psychology, 96(4), 467-491. https://doi.org/10.1348/000712605X53533

Dittmar, H. (2005b). A new look at "compulsive buying": Self-discrepancies and materialistic values as predictors of compulsive buying tendency. Journal of Social and Clinical Psychology, 24, 832-859. https://doi.org/10.15 21/jscp.2005.24.6.832

Dittmar, H., Bond, R., Hurst, M., \& Kasser, T. (2014). The relationship between materialism and personal well-being: A meta-analysis. Journal of personality and social psychology, 107, 879. https://doi.org/10.1037/a0037409

Dogan, V., \& Torlak, O. (2014). The Relationship Between Symbolic Money Meanings and Materialism. Business and Economics Research Journal, 5, 1-17.

Eastman, J. K., Calvert, S., Campbell, D., \& Fredenberger, B. (1997). The relationship between status consumption and materialism: a cross-cultural comparison of Chinese, Mexican and American students. J. Mark. Theory Pract., 5, 5266. https://doi.org/10.1080/10696679.1997.11501750

Ersoy-Quadir, S. (2012). An Analysis of Some of the Factors Behind Materialism Among University Students in Turkey. Journal of Adult Development, 19, 79-87. https://doi.org/10.1007/s10804-011-9136-9

Faber, R. J., \& Christenson, G. A. (1996). In the mood to buy: Differences in the mood states experienced by compulsive buyers and other consumers. Psychology \& Marketing, 13, 803-819. https://doi.org/10.1002/(SICI)15206793(199612)13:8<803::AID-MAR6>3.0.CO;2-J

Fischer, E., \& Arnold, S. J. (1990). More than a labor of love: Gender roles and Christmas gift shopping. J. Consum. Res., 17, 333-344. https://doi.org/10.1086/208561

Fitzmaurice, J., \& Comegys, C. (2006). Materialism and social consumption. J. Mark. Theory Pract., 14, $287-299$. https://doi.org/10.2753/MTP1069-6679140403

Flouri, E. (2004). Exploring the relationship between mothers' and fathers' parenting practices and children's materialist values. Journal of Economic Psychology, 25, 743-752. https://doi.org/10.1016/j.joep.2003.06.005

Flynn, L. R., Goldsmith, R. E., \& Kim, W. M. (2013). A cross-cultural study of materialism and brand engagement. Journal of Multidisciplinary Research, 5, 49-70.

Froh, J. J., Emmons, R. A., Card, N. A., Bono, G., \& Wilson, J. A. (2011). Gratitude and the reduced costs of materialism in adolescents. Journal of Happiness Studies: An Interdisciplinary Forum on Subjective Well-Being, 12, $289-302$. https://doi.org/10.1007/s10902-010-9195-9

Fu, X., Kou, Y., \& Yang, Y. (2015). Materialistic values among Chinese adolescents: Effects of parental rejection and selfesteem. Child \& Youth Care Forum, 44, 43-57. https://doi.org/10.1007/s10566-014-9269-7

Ger, G., \& Belk, R. W. (1996). Cross-cultural differences in materialism. Journal of economic psychology, 17, 55-77. https://doi.org/10.1016/0167-4870(95)00035-6

Gilovich, T., Kumar, A., \& Jampol, L. (2015). A wonderful life: Experiential consumption and the pursuit of happiness. Journal of Consumer Psychology, 25(1), 152-165. https://doi.org/10.1016/j.jcps.2014.08.004

Goldberg, M. E., Gorn, G. J., Peracchio, L. A., \& Bamossy, G. (2003). Understanding materialism among youth. Journal of consumer psychology, 13, 278-288. https://doi.org/10.1207/S15327663JCP1303_09

Goldsmith, R. E., Flynn, L. R., \& Clark, R. A. (2011). Materialism and brand engagement as shopping motivations. Journal of Retailing and Consumer Services, 18, 278-284. https://doi.org/10.1016/j.jretconser.2011.02.001

Harnish, R. J., Bridges, K. R., Gump, J. T., \& Carson, A. E. (2019). The maladaptive pursuit of consumption: The impact of materialism, pain of paying, social anxiety, social support, and loneliness on compulsive buying. International Journal of Mental Health and Addiction, 17, 1401-1416. https://doi.org/10.1007/s11469-018-9883-y

Ho, H., Shin, W., \& Lwin, M.O. (2019). Social networking site use and materialistic values among youth: The safeguarding role of the parent-child relationship and self-regulation. Communication Research, 46, 1119-1144. https://doi.org/10.1177/0093650216683775

Hofmeister, A., \& Neulinger, A. (2013). Characteristics of materialism and its measurement: assessing the Belk's materialism scale in Hungary. International Journal of Consumers Studies, 37, 320-326. https://doi.org/10.11 $11 /$ ijcs.12001 
International Monetary Fund. Available online: https://www.imf.org/external/pubs/ft/weo/2018/02/weodata/groups.htm\#ae (accessed on 8 February, 2021).

Islam, T., Sheikh, Z., Hameed, Z., Khan, I. U., \& Azam, R. I. (2018). Social comparison, materialism, and compulsive buying based on stimulus-response-model: a comparative study among adolescents and young adults. Young Consumers, 19, 19-37. https://doi.org/10.1108/YC-07-2017-00713

Islam, T., Wei, J., Sheikh, Z., Hameed, Z., \& Azam, R. I. (2017). Determinants of compulsive buying behavior among young adults: The mediating role of materialism. Journal of adolescence, 61, 117-130. https://doi.org/10.10 16/j.adolescence.2017.10.004

Jaspers, E. D., \& Pieters, R. G. (2016). Materialism across the life span: An age-period-cohort analysis. Pers. Soc. Psychol. Bull. , 111, 451-473. https://doi.org/10.1037/pspp0000092

Jiang, W., Liu, H., \& Jiang, J. (2020). The Development of Materialism in Emerging Adulthood: Stability, Change, and Antecedents. Pers. Soc. Psychol. Bull., 41, 1276-1290. https://doi.org/10.1177/0146167220925234

Kamineni, R. (2005). Influence of materialism, gender, and nationality on consumer brand perc., 14, 25-32. https://doi.org/10.1057/palgrave.jt.5740167

Kasser, T. (2002). The high price of materialism, MIT press, Cambridge, MA. https://doi.org/10.7551/mitpress/ 3501.001 .0001

Kasser, T., \& Ryan, R. M. (1993). A dark side of the American dream: Correlates of financial success as a central life aspiration. Pers. Soc. Psychol. Bull., 65, 410. https://doi.org/10.1037/0022-3514.65.2.410

Kasser, T., \& Ryan, R.M. (1996). Further examining the American dream: Differential correlates of intrinsic and extrinsic goals. Pers. Soc. Psychol. Bull., 22, 280-287. https://doi.org/10.1177/0146167296223006

Kasser, T., Ryan, R. M., Zax, M., \& Sameroff, A. J. (1995). The relations of maternal and social environments to late adolescents' materialistic and prosocial values. Developmental psychology, 31, 907. https://doi.org/10.1037/0012 1649.31.6.907

Keech, J., Papakroni, J., \& Podoshen, J. S. (2020). Gender and differences in materialism, power, risk aversion, selfconsciousness, and social comparison. J. Int. Consum. Mark., 32, 83-93. https://doi.org/10.1080/08961530. 2019.1647125

Kilbourne, W., Grunhagen, M., \& Foley, J. (2005). A cross-cultural examination of the relationship between materialism and individual values. Journal of Economic Psychology, 26, 624-641. https://doi.org/10.1016/j.joep.2004.12.009

Kim, H., Callan, M. J., Gheorghiu, A. I., \& Matthews, W. J. (2017). Social comparison, personal relative deprivation, and materialism. Br. J. Soc. Psychol., 56, 373-392. https://doi.org/10.1111/bjso.12176

King, R. B., \& Datu, J. A. D. (2017). Materialism does not pay: Materialistic students have lower motivation, engagement, and achievement. Contemporary Educational Psychology, 49, 289-301. https://doi.org/10.1016/j.cedpsych.20 17.03.003

Kruger, D., \& Byker, D. (2009). Evolved foraging psychology underlies sex differences in shopping experiences and behaviors. Journal of Social, Evolutionary, and Cultural Psychology, 3, 328-342. https://doi.org/10.1037/h0099312

Ku, L., Dittmar, H., \& Banerjee, R. (2014). To Have or to Learn? The Effects of Materialism on British and Chinese Children's Learning. Journal of Personality and Social Psychology, 106, 803-821. https://doi.org/10.1037/a0036038

La Barbera, P. A., \& Gurhan, Z. (1997). The role of materialism, religiosity, and demographics in subjective well-being. Psychology \& Marketing, 14, 71-97. https://doi.org/10.1002/(SICI)1520-6793(199701)14:1<71::AID-MAR5>3. $0 . \mathrm{CO} ; 2-\mathrm{L}$

Lau, A. K. W, Tang, E., \& Yam R. C. M. (2010). Effects of suppliers and customer integration on product innovation and performance: empirical evidence in Hong Kong manufacturers. Journal of Product Innovation Management, 27, 761777. https://doi.org/10.1111/j.1540-5885.2010.00749.x

Lewallen, J., Miller, B., \& Behm-Morawitz, E. (2016). Lifestyles of the rich and famous: Celebrity media diet and the cultivation of emerging adults' materialism. Mass Communication and Society, 19, 253-274. https://doi.org/10.10 80/15205436.2015.1096945

Li, J., Lu, M., Xia, T., \& Guo, Y. (2018). Materialism as compensation for self-esteem among lower-class students. Personality and Individual Differences, 131, 191-196. https://doi.org/10.1016/j.paid.2018.04.038

Li, M., Zhao, T., Huang, E., \& Li, J. (2020). How does a public health emergency motivate People's impulsive consumption? an empirical study during the COVID-19 outbreak in China. International Journal of Environmental Research and Public Health, 17(14), 5019. https://doi.org/10.3390/ijerph17145019 
Liobikiene, G., Liobikas, J., Brizga, J., \& Juknys, R. (2020). Materialistic values impact on pro-environmental behavior: The case of transition country as Lithuania. Journal of Cleaner Production, 244, 118859. https://doi.org/10.10 16/j.jclepro.2019.118859

Maison, D., \& Adamczyk, D. (2020). The relations between materialism, consumer decisions and advertising perception. Procedia Computer Science, 176, 2526-2535. https://doi.org/10.1016/j.procs.2020.09.320

Mandy, C. A. (2018). Differences in the demographic characteristics of highly materialistic consumers and those whose clothing consumption practices reflect material simplicity, Dissertation, URI: http://hdl.handle.net/2263/70401.

Maraz, A., Griffiths, M. D., \& Demetrovics, Z. (2016). The prevalence of compulsive buying: a meta-analysis. Addiction, 111, 408-419. https://doi.org/10.1111/add.13223

Martin, C., Czellar, S., \& Pandelaere, M. (2019). Age-related changes in materialism in adults-A self-uncertainty perspective. J. Res. Pers., 78, 16-24. https://doi.org/10.1016/j.jrp.2018.09.007

Micken, K. S. (1993). Materialism and the Self. Dissertation. https://doi.org/10.25777/pjk8-0606.

Moldes, O., \& Ku, L. (2020). Materialistic cues make us miserable: A meta-analysis of the experimental evidence for the effects of materialism on individual and societal well-being. Psychology \& Marketing, 37, $1396-1419$. https://doi.org/10.1002/mar.21387

Moschis, G. P. (2007). Life course perspectives on consumer behavior. Journal of the Academy of Marketing Science, 35(2), 295-307. https://doi.org/10.1007/s11747-007-0027-3

O'Guinn, T. C., \& Faber, R. J. (1989). Compulsive buying: A phenomenological exploration. J. Consum. Res., 16, 147157. https://doi.org/10.1086/209204

Ozgen, O., \& Esiyok, E. (2020). Consumer ethics, materialism and material satisfaction: A study on Turkish adolescent consumers. Int. J. Consum. Stud., 44, 14-24. https://doi.org/10.1111/ijcs.12541

Parashar, S., \& Jain, S. (2017). Effect of Demographics on Materialism: An Empirical Study. Pacific Business Review International, 10, 124-132.

Podoshen, J. S., \& Andrzejewski, S. A. (2012). An examination of the relationships between materialism, conspicuous consumption, impulse buying, and brand loyalty. J. Mark. Theory Pract., 20, 319-334. https://doi.org/10.275 3/MTP1069-6679200306

Ponchio, M. C., \& Aranha, F. (2008). Materialism as a predictor variable of low-income consumer behaviour when entering into installment plan agreements. Journal of Consumer Behaviour: An International Research Review, 7, 21-34. https://doi.org/10.1002/cb.234

Richins, M. (2004). The material values scale: Measurement properties and development of a short form. J. Consum. Res., 31, 209-219. https://doi.org/10.1086/383436

Richins, M., \& Fournier, S. (1991). Some theoretical and popular notions concerning materialism. Journal of Social Behaviour and Personality, 6, 403-414.

Richins, M., \& Dawson, S. (2004). The material values scale: measurement properties and development of a short form. $J$. Consum. Res., 31, 209-219. https://doi.org/10.1086/383436

Richins, M. L., \& Chaplin, L. N. (2015). Material parenting: How the use of goods in parenting fosters materialism in the next generation. J. Consum. Res., 41, 1333-1357. https://doi.org/10.1086/680087

Richins, M. L., \& Dawson, S. (1992). A consumer values orientation for materialism and its measurement: Scale development and validation. J. Consum. Res., 19, 303-316. https://doi.org/10.1086/209304

Rindfleisch, A., Burroughs, J. E., \& Denton, F. (1997). Family structure, materialism, and compulsive consumption. Journal of consumer research, 23(4), 312-325. https://doi.org/10.1086/209486

Roberts, J. A., Manolis, C., \& Tanner, Jr, J. F. (2003). Family structure, materialism, and compulsive buying: A reinquiry and extension. Journal of the Academy of Marketing Science, 31(3), 300-311. https://doi.org/10.1177/00920 70303031003007

Roberts, J. A., \& Clement, A. (2007). Materialism and Satisfaction with Over-All Quality of Life and Eight Life Domains. Social Indicators Research, 82, 79-92. https://doi.org/10.1007/s11205-006-9015-0

Roberts, J. A., Manolis, C., \& Tanner J. F. (2008). Interpersonal influence and adolescent materialism and compulsive buying. Social Influence, 3, 114-131. https://doi.org/10.1080/15534510802185687

Santini, F. O., Ladeira, W. J., Sampaio, C. H., \& Araujo, C. F. (2017). Meta-analysis of the antecedent and consequent constructs of materialism. Rev. Bus. Manag., 19, 538-556. https://doi.org/10.7819/rbgn.v0i0.2931

Schaefer, A. D., Hermans, C. M., \& Parker, R. S. (2004). A cross-cultural exploration of materialism in adolescents. Int. J. Consum. Stud., 28, 399-411. https://doi.org/10.1111/j.1470-6431.2004.00395.x 
Schalembier, B., Bleys, B., Van Ootegem, L., \& Verhofstadt, E. (2020). How the income of others affects the life satisfaction of materialists. Journal of Economic Behavior \& Organization, 174, 64-74. https://doi.org/10.10 16/j.jebo.2020.03.022

Segal, B., \& Podoshen, J. S. (2013). An examination of materialism, conspicuous consumption and gender differences. Int. J. Consum. Stud., 37, 189-198. https://doi.org/10.1111/j.1470-6431.2012.01099.x

Sheldon, K. M., \& Lyubomirsky, S. (2004). Achieving sustainable new happiness: Prospects, practices, and prescriptions. Positive psychology in practice, 127-145. https://doi.org/10.1002/9780470939338.ch8

Shrum, L. J., Wong, N., Arif, F., Chugani, S. K., Gunz, A., Lowrey, T. M., \& Scott, K. (2013). Reconceptualizing materialism as identity goal pursuits: Functions, processes, and consequences. Journal of Business Research, 66, 1179-1185. https://doi.org/10.1016/j.jbusres.2012.08.010

Song, W., Jin, X., Gao, J., \& Zhao, T. (2020). Will buying follow others ease their threat of death? An analysis of consumer data during the period of COVID-19 in China. International journal of environmental research and public health, 17(9), 3215. https://doi.org/10.3390/ijerph17093215

Tarka, P. (2020). Influence of materialism on compulsive buying behavior: General similarities and differences related to studies on young adult consumers in Poland and US. J. Int. Consum. Mark., 32, 243-267. https://doi.org/10.10 80/08961530.2019.1695240

Twenge, J. M., \& Kasser, T. (2013). Generational changes in materialism and work centrality, 1976-2007: Associations with temporal changes in societal insecurity and materialistic role modeling. Pers. Soc. Psychol. Bull., 39, $883-897$. https://doi.org/10.1177/0146167213484586

Usher, K., Durkin, J., \& Bhullar, N. (2020). The COVID-19 pandemic and mental health impacts. International Journal of Mental Health Nursing, 29(3), 315. https://doi.org/10.1111/inm.12726

Verdugo, G. B., \& Ponce, H. R. (2020). Gender Differences in Millennial Consumers of Latin America Associated with Conspicuous Consumption of New Luxury Goods. Global business review, 17, 1269-1279. https://doi.org/10.11 77/0972150920909002

Wang, R., Liu, H., Jiang, J., \& Song, Y. (2017). Will materialism lead to happiness? A longitudinal analysis of the mediating role of psychological needs satisfaction. Personality and Individual Differences, 105, 312-317. https://doi.org/10.10 16/j.paid.2016.10.014

Wong, N., Rindfleisch, A., \& Burroughs J. E. (2003). Do reverse-worded items confound measures of cross-cultural consumer research, the case of the material values scale? J. Consum. Res., 30, 72-91. https://doi.org/10.1086/374697

Workman, J. E., \& Lee, S. H. (2011). Materialism, fashion consumers and gender: A cross-cultural study. Int. J. Consum. Stud., 35, 50-57. https://doi.org/10.1111/j.1470-6431.2010.00935.x

World Bank. Available online: https://datahelpdesk.worldbank.org/knowledgebase/articles/906519\#High_income (accessed on 7 February 2021).

Yang, S., \& Stening, B. W. (2016). Antecedents of materialism in China-an intergenerational analysis. Int. J. Consum. Stud., 40, 701-711. https://doi.org/10.1111/ijcs.12284

Yurchisin, J., \& Johnson, K. K. (2004). Compulsive buying behavior and its relationship to perceived social status associated with buying, materialism, self-esteem, and apparel-product involvement. Fam. Consum. Sci. Res. J., 32, 291-314. https://doi.org/10.1177/1077727X03261178

Zhang, Y., Hawk, S. T., Opree, S. J., de Vries, D. A., \& Branje, S. (2020). "Me","We" and Materialism: Associations between Contingent Self-Worth and Materialistic Values across Cultures. The Journal of psychology, 154, 386-410. https://doi.org/10.1080/00223980.2020.1759496

Zhou, F. (2009). Income gap, materialism, and attitude toward the rich in developing countries. In Peace psychology in Asia; Springer, New York, NY, 275-286. https://doi.org/10.1007/978-1-4419-0143-9_15

\section{Authors' biographies}

Dalia Antiniene is a Ph.D. in social sciences and is a professor at the Lithuanian University of Health Sciences, Department of Health Psychology. She is the author of three monographs and two research studies. She has published her work in national and international conferences and research papers. Her spheres of scientific interest include EI, social competence, ego identity, cognitive abilities, etc.

Beata Šeinauskienė is an Associate Professor at the KTU School of Economics and Business. Her current research interests include the impact of cognitive coping strategies on consumer materialism and maladaptive consumption. She regularly participates in international scientific conferences and internships. Her membership in EMAC and AMA allows her to interact with marketing academics and practitioners. She has been the leader of an interdisciplinary research group focused on consumer materialism since 2016. 
Aušra Rūtelionė is senior researcher and assoc. professor at KTU School of Economics and Business, Sustainable Management Research Group. Research interests are: consumer materialism, sustainable consumption behaviour, pro-social and pro-environmental engagement in sustainable consumption, marketing approaches for circular economy. A. Rutelione was (is) the manager or researcher of more than $30 \mathrm{R} \& \mathrm{D}$ and development projects. Researcher is the member of American Marketing Association and European Marketing Association.

Shahrokh Nikou is a Docent in Information Systems and a senior lecturer at the Faculty of Social Sciences, Business and Economics, Åbo Akademi University and affiliated with Stockholm University. He is interested in digitalisation, higher education, digital platforms, entrepreneurship, research methods, and digital business. He has practical and academic experience in business model and business model innovation. He has published more than 80 peer-reviewed articles and is an Associate Editor in the Journal of Digital Business, AE in the Journal of Electronic Market, Section Editor in the Journal of Theoretical and Applied Electronic Commerce Research, an Academic Editor of PLOSONE.

Rosita Lekavičienè is a professor at the Kaunas University of Technology (Lithuania), expert at Research Council of Lithuania, Public Institution Lithuanian Business Support Agency, and other. Currently she conducts research and creates psychodiagnostic methodologies in the field of emotional intelligence, social competence and national identity. She has published two monographs, two research studies, more than 40 scientific articles, and regularly participates in international conferences. R. Lekaviciene is a co-author of several psychology textbooks and other study literature.

The article has been reviewed. Received in March 2021; accepted in October 2021.

This article is an Open Access article distributed under the terms and conditions of the Creative Commons Attribution 4.0 (CC BY 4.0) License (http://creativecommons.org/licenses/by/4.0/). 